\title{
POSSIBILIDADE DA UTILIZAÇÃO DA ARBITRAGEM NO ÂMBITO DE UMA RELAÇÃO DE CONSUMO
}

André Gil Dorothoto

Resumo:

A arbitragem, por ser legitimada pelo princípio da autonomia da vontade, encontra resistência de grande parte da doutrina quando pretende intermediar as relações de consumo.

Conforme o art. $4^{\circ}$. parágrafo $2^{\circ}$ da Lei de Arbitragem prevê que "Nos contratos de adesão, a cláusula compromissória só terá eficácia se o aderente tomar a iniciativa de instituir a arbitragem ou concordar, expressamente, com sua instituição, desde que por escrito em documento anexo ou em negrito, coin a assinatura ou visto especialmente para essa cláusula." Entretanto, dada a condição de hipossuficiência do contratanteaderente, comum às relações de consumo, este poderá alegar vício no consentimento, sob o argumento de que o contratado, responsável pela elaboração do contrato de adesão, detém posição significativamente superior à sua, técnica ou economicamente etc. Ademais, o Código do Consumidor, em seu art. 51, especifica serem nulas de pleno direito as cláusulas contratuais que determinem utilização compulsória de arbitragem.

Palavras-chave: Arbitragem. Consumidor. Contrato de adesão.

\begin{abstract}
:
Arbitration, legitimated by the autonomy of the will principle, is challenged by most scholars in relation to its use in consumer relationships. According to the article $4^{\circ}$, paragraph $2^{\circ}$ of the Law of Arbitration, "in adhesion contracts, the compromissory clause shall only be effective if the party has the initiative to institute the arbitration or to agree with it expressly, since in writing in enclosed document or in bold. with the signature or visa especially for that clause.' However. given the condition of the weak party, inherent to consumer relationships, he can argue vice of consent, by stating that the party who drafted the adhesion contract has more contractual, technical or economic power than him. Besides, Brazilian Consumer Code, art. 51 , disposes that contractual terms that impose arbitration shall be void.
\end{abstract}

Keywords: Arbitration. Consumer. Adhesion Contract.

O objetivo desse artigo é a veriticação da possibilidade da utilização da arbitragem para solucionar controvérsias nas quais uma das partes scja consumidor, ou seja, para dirimir um conflito que tenha surgido no âmbito de uma relação de consumo.

Aluno de graduação da Faculdade de Direito da I'niversidade de São Paulo. 
Com esse intuito, am primeiro lugar, deve-se deixar clara a disponibilidade da relação jurídica que envolve consumidor ¿ fornecedor, o que significa que "podem as partes, diante de um litigio que diga respeito ao fornecimento de bens e serviços, transigir, desisti, ou renunciar aos respectivos direitos" (por exemplo, se um consumidor adquirir produto viciado, tem o dircito de reclamar e pedir a substituição do produto, a restituição da quantia paga ou o abatimento proporcional do preço art. $18, \S$ $1^{\circ}, \mathrm{CDC}$-, mas, poderá também renunciar a ele, ou negociá-lo com o fornecedor, transigindo para encontrar uma solução mais satisfatória para ambas as partes).

Em segundo lugar, nota-se que. se os direitos são disponíveis, podendo as partes a respeito deles contratar, por outro lado, a Lei de Defesa do Consumidor é uma lei de ordem pública, ${ }^{2}$ não podendo seus preceitos serem afastados por disposições das partes.

O Código de Defesa do Consumidor estipula, por exemplo, a nulidade das cláusulas abusivas - aquelas que desequilibram significativamente a comutatividade das obrigações, seja atenuando as do contratante mais forte, seja agravando as do mais fraco pois chocam-se com o princípio da justiça contratual, que é um dos fundamentos de todo o sistema de proteção ao consumidor.

F, tal princípio não pode ser colocado de lado, pois estabelecido para a defesa daqueles que vierem a contratar com uma parte econômica ou politicamente mais forte. ${ }^{3}$

Para os fins dessa pesquisa, destaca-se o inciso VII do art. 51 que estabelece serem abusivas e, portanto, "nulas de pleno direito, entre outras, as cláusulas contratuais relativas ao fornecimento de produtos e serviços que determinem a utilização compulsória da arbitragem"

Nota-se que, neste aspecto, a preocupação do legislador foi evitar que o fornecedor, utilizando-se de sua vantagem econômica, estipulasse que eventual controvérsia decorrente de um certo contrato fosse, impreterivelmente. resolvida por árbitros, o que comprometeria o princípio da equidade, também basilar no direito do

CARMONA. Carlos Alberto. Arbitragem e Processo: um comentário à Lei n. 9.307/96. São Paulo: Malheiros, 1998. p. 57.

2 Nesse sentido, determina o seu art. 10: "O presente Código estabelect normas de proteção e defesa do consumidor, de ordem puiblica e interesse social, nos termos dos arls. $5^{\circ}$. inciso XXXII. 170. inciso V. da Constituição Federal e art. 48 de suas Disposiçōes Transitórias

3. $\dot{E}$ interessante observar que o Código de Defesa do Consumidor surgiu num momento em que o Estado passou a estabelecer normas para proteger a parte mais fraca, a fim de restaurar o equilibrio contratual, fragilizado pela desigualdadi económica das partes, o que nào mais justificava o principio da irrestrita liberdade para estabelecer as cláusu as contratuais. Orlando Gomes. nesse sentido, esclarece que. se "partes livres e iguais não precisuvum da interferência legislativa para impedir a estipulação de obrigaçōes onerosas ou vexatórias". tal interferência fez-se necessária quando passou-se a mal usar essa liberdade. com o estabelecimento, por exempio. de obrigações abusivas pela parte econonicamente mais forte do contrato (Contratos, p. 26). 
consumidor, já que esse não poderia se dirigir ao Judiciário e veria o conflito dirimido por um particular, havendo riscos de comprometimento deste com o fornecedor. ${ }^{4}$

Acontece que, antes da nova lei de arbitragem, esse dispositivo não tinha muita razão de ser, dada a ausência de uma maneira de se estipular no contrato a obrigatoriedade da utilização da arbitragem para solução de eventual litígio, pois a cláusula compromissória, como visto, era tida como mero pré-contrato de compromisso. não podendo ser objeto de execução específica: de modo que, uma vez inserida num contrato, e surgido um conflito, a arbitragem só se instauraria com a celebração do compromisso pelas partes (ou seja, não obrigatoriamente).

Mas, com a Lei n. 9.307/96, na mesma siluação, as partes são obrigadas a resolver o litígio por meio da arbitragem, podendo a parte renitente ser demandada judicialmente para celebrar o compromisso (art. $7^{\circ}$ ).

Chega-se, então, ao choque entre a estipulação do art. $3^{\circ}$ da Lei de Arbitragem, que prevê a possibilidade de as partes submeterem a solução de seus litígios ao juizo arbitral através da cláusula compromissória, e o art. 51, VII do CDC, que comina de nulidade tal cláusula quando estabelecida nos contratos de consumo.

Após alguma discussão, ${ }^{5}$ a doutrina parece ter alcançado o consenso no sentido de que a Lei de Arbitragem não derrogou o referido artigo do CDC, que continua em pleno vigor. ${ }^{\circ}$ de forma que serão nulas as cláusulas compromissórias estipuladas em contratos de consumo.

4 ETCHEVERY, afirmando o comprometimento dos árbitros com aqueles por quem foram indicados, $\dot{E}$ eloqüente: "A paz social resultante da atuaçào de árbitros impostos por quem detém o poder econômico seria algo como a paz dos cemitérios, se comparada à que resulta da aplicação da justiça por juizes logados. Estes últimos, para assegurar sua isenção, dispõem das garantias da vitaliciedade, inamovibilidade ' da irredutibilidade dos seus vencimentos, que são fixados por lei e pagos pelo Estado e nãu por um delerminado cmpresário. Não são escolhidos e impostos, inapelavelmente, pela parte que tem interesse na solução do conflito" (A nova Lei de Arbitragem e os Contratos de Adesào, p. 54).

s Na realidade, logo após a promulgação da Lei de Arbitragem, surgiram inúmeras criticas, quer afirmando a inconstitucionalidade de suas disposições acerca da cláusula arbitral, quer porque entendia-se que pretendia revogar o art. 51, VII, do $\mathrm{CDC}$, quer porque possibilitava a inserção da cláusula arbitral em contratos de adesão. Mas, após algum estudo, a questão da inconstitucionalidade quase já se superou, e observou-se que a Lei não previa a revogação daquele artigo do ('ódigo de Defesa do Consumidor, que mantêm-se vigente e levando à nulidade as cláusulas arbitrais inseridas em contratos de consumo (o que aconteceu foi que o então Projeto $780 / 92$ do Senado previa a derrogação expressa do art. 51. VII do CDC, mas era outra a redação do art. $4^{\circ}, \S 2^{\circ}$ do Projeto, de forma que tornava-se sem grande relevância a determinação do CDC - vide nota). Carlos Alberto Carmona, desde a promulgação da lei já ensinava: "Descarlou-se a validade de uma cláusula compromissória em contrato que discipline relação de consumo, sem que isso signifique a impossibilidade de introduzir-se a arbitragem pela via do compromisso: surgida a controvérsia, podem as partes, de comum acordo. celebrar "ompromisso arbitral para submeter o dissenso à soluçáo de árbitros " (Arbitragem e processo: um comentário à Lei n. 9.307i)6, p. 57).

6 Leonardo Valles Bento, no entanto, após explicar a igual hierarquia e especialidade do CDC e da Lei n. 9.307/96, conclui que, como essa "admile expressamente a cláusula compromissória em contratos de adesão - todos eles - bem assim a sua execução especifica". não se pode mais "sustentar a vigência da 
A esse entendimento se chegou ora se propugnando a especialidade do CDC frente a Lei de Arbitragem, ora justificando a não revogação do art. 51, VII do CDC pelo seu caráter público e pela falta de disposição especifica naquela outra lei, a prever a revogação do referido artigo.?

Sobretudo, parece interessante anotar o entendimento de Antônio Junqueira de Azevedo, no sentido de que o conflito entre o que dispõe o CDC e a Lei de Arbitragem é mais um conflito de filosofia do que um conflito de regras. ${ }^{8}$

Esse ilustre professor, após contextualizar os momentos de criação do Código Civil, ('ódigo de Defesa do Consumidor e Lei de Arbitragem, concluiu que, da mesma forma que não houve revogação do princípio contratual básico do Código Civil, qual seja, o da autonomia da vontade. quando da promulgação do CDC, que veio, ao revés, acrescentar outros princípios à teoria dos contratos, aumentando a sua complexidade; ; a Lei de Arbitragem também não suprimiu as disposições do CDC, mas com ele tem de se compatibilizar, conforme a Constituição Federal, cabendo ao intérprete esse trabalho.

Assim. a Lei de Arbitragem nada alterou o CDC, sobre os direitos do consumidor, de forma que as cláusulas compromissórias presentes em contratos de consumo são nulas de pleno direito, porque há uma presunção da sua abusividade.

Mas, tal afirmação não quer dizer que os conflitos decorrentes de contratos de consumo não podem ser resolvidos pelo juízo arbitral.

proihição do Código. (...) de maneira que ela (clánsula arbitral) já não mais poderà ser considerada nula do pleno iure. Todavia. isso não significa que a arbitragem nào possa ser considerada eventualmente abusiva, pelo seu enquadramento na cláusula geral do art. $51, I V$ do $C D C$, ou, de resto. em virtude da violação da ordem pública intracontratual" $F$, na seqüência, o autor coloca as condições para a validade da arbitragem determinada por cláusula arbitral presente em contrato de consumo, a suber, devem ser respeitadas as regras do $C D C$, não pode o juizo arbitral reportar-se às normas de uma càmara de arbitragem completamente estranha ao consumidor, e, o ärbitro deve ter a confiança de ambas as partes, o que exige, dada a hipossuficiência do consumidor, que seja um técnico de uma entidade de defesa do consumidor. (Arbitrabilidade dos litigios de consumo, p. 4).

Vide. por exemplo, SHICiULMA TSU. Plínio José I.opes. A Problemática da Cláusula Compromissória nos Contratos de Adesão. In: CASELLA, Paulo BORBA. Arbitragem: lei brasileira e praxe internacional. $2 \mathrm{~cd}$. São Paulo: LTr, 1999. p. 438-449; FILOMENO, José Geraldo Brito. Conflitos de Consumo e Juízo Arbitral. Direilo do Consumidor, n. 21, p. 39-50, jan./mar. 1997; ETCHEVERRY, Carlos Alberto op. cil.. p. 51 - 60.

* AZEVEDO, Antônio Junqueira de. A arbitragem e o Direito do Consumidor. Direito do Consumidor, n. 23, p. 33-40, jul./set. 1997.

"A moderna teoria dos contratos postula a existéncia de uma ordem pública contratual, constituida de três principios: autonomia privada, justiça contratual e boa-fé. () primeiro consiste na possibilidade das pessoas buscarem livremente a salisfação de seus interesses mediante a celebração de negócios jurídicus; a justiça contratual está ligada à idéia de igualdade nas condiçōes de contratação. com vistas a assegurar um equilibrio nas obrigações correspectivas das partes; e. a boa-fé compreende todos aqueles deveres de lisura e honestidade que devem permear todos os momentos da vida do contrato, das negociaçōes preliminarcis atí à execução das obrigaçòes e mesmo depois dela, em certos casos. 
Como já dito, os direitos envolvidos na relação de consumo são disponíveis, podendo as partes a respeito deles contratar, sendo permitido, então, celebrarem o compromisso arbitral, após o surgimento de um conflito, para que esse seja solucionado pela arbitragem. ${ }^{10}$ Se houver abuso, este deverá ser examinado, mas in concreto, não havendo a sua pressuposição pela lei a priori. ${ }^{\text {" }}$

Em conclusão, explica-se que a arbitragem pode ser meio para a solução de controvérsias surgidas no âmbito das relações de consumo, ${ }^{12}$ mas sua utilização só pode ser determinada por meio de compromisso. As cláusulas compromissórias estipuladas em contratos de consumo são nulas de pleno dircito, de acordo com determinação expressa do CDC, que não foi revogada pela Lei n. 9.307/96.

Neste ponto. deve-se esclarecer a diferença entre contrato de consumo e contrato de adesão, pois o art. $4^{\circ} \S 2^{\circ}$ da Lei n. 9.307/96 permite a instauração de arbitragem baseada em cláusula arbitral inserida em contrato de adesão, e não há nessa prescrição qualquer contradição com o que já foi exposto. ${ }^{13}$

Contrato de adesão, segundo Orlando Gomes, é aquele no qual "uma das partes tem de aceitar, em bloco, as cláusulas estabelecidas pela outra, aderindo a uma situação contratual que encontra definida em todos os seus termos. O consentimento manifesta-se como simples adesâo a conteuido preestabelecido da relação juridica" 14

Verifica-se que, num primeiro momento, o empresário formula um esquema contratual abstrato, redigindo as cláusulas do conteúdo das relações contratuais que pretende concluir uniformemente com pessoas indeterminadas; e que, tal prática denota

10 Nesse sentido. explicam Arruda Alvim e outros que "o Código não impede a ulilização de compromisso arbitral. que, ademais, tem se revelado como eficiente meio de solução de litigios de corısumo nos paises desenvolvidos. Por isso, podem as parles louvar-se de árbitros para resolver suas pendencias, firmando. para tanto, compromisso arbitral" (Código do Consumidor Comentado, p. 253), e Nelson Nery Jr. completa: "o juizo arbitral é importante fator de composição de litígios de consumo, razão por que o Código não quis proibir sua constitliç̧áo pelas partes do contrato de consumo: a interpretação a contrário sensu da norma sob comentário (art. 5l. VII. CDC) indicu que. nào sendo determinada compulsoriamente, $\dot{e}$ possivel instituir-se a arbitragem" (AI.VIM, Arruda: ALVIM, Thereza: ALVIM, Fduardo Arruda; MARINS, James. Código do Consumidor Comentado. 2. ed. São Paulo: Revista dos Tribunais, 1995).

11 É de lembrar-se, ainda, que a arbitragem que se seguirá nesse caso terá de ser decidida sem ferir as normas cogentes do CDC.

$12 \mathrm{O}$ art. $4^{\circ}, \mathrm{V}$ do CDC fala mesmo em "incentivo à criação (...) de mecanismos alternativos de solução de controvérsias" de nodo que a arbitragem deve ser incentivada por entidades representativas da indústria, do comércio, e dos consumidores.

13 Bem aponta Márcio Oliveira Puggina que "a leitura apressada do art. $4^{\circ}$. \$ $2^{\circ}$. da Lei n. 9.307 pode dar a entender que a admissão da inserção da cláusula compromissória em contratos de adesão permitiria, também. o seu estabelecimento èn contrato de adesão referente a relações de consumo" Mas, "qualquer tentativa de interpretação neste sentido esbarraria no histórico da tramitação do projeto que resultou na Lei n. 9.307" (PUGGINA, Marcio Oliveira. Arbitragem ou jurisdição privada? Ajuris: Revista da Associação dos Juizes do Rio Grande do Sul, v. 24. n. 69. p. 359-368, mar. 1997). 
sua superioridade negocial, já que não apenas procura otimizar sua atividade econômica, no tocante à eliminação do tempo que seria gasto com negociações individuais, como também configurar o regime que lhe é mais favorável.

Após a redação do "contrato de adesão" o eventual cliente da empresa adere a esse esquema, travando-se entre os dois uma relação juridica de caráter negocial, com direitos e obrigações correlatas, sem yualquer conexão jurídica com os outros vínculos que, do mesmo modo e com igual conteúdo, se formam com distintos sujeitos.

Caracteriza-se, assim, pelo fato de um dos contratantes não ter a liberdade para discutir os termos do contrato, podendo apenas aceitá-lo ou recusá-lo; e, na maioria das situações, terá de aceitá-lo, dada a necessidade de adquirir o bem jurídico que é objeto do contrato (além disso, o aderente se veria, provavelmente, colocado diante das mesmas condições negociais, caso buscasse contratar com outra pessoa).

O CDC, em seu Capitulo VI, preocupou-se em regular esse tipo de contrato, para que não surgissem abusos por parte do contratante que impõe as suas cláusulas.

Assim, o art. 54 estabelece: "Contrato de adesão é aquele cujas cláusulas tenhum sido aprovadas pela autoridade competente ou estabelecidas unilateralmente pelo fornecedor de produtos ou serviços, sem que o consumidor possa discutir ou modificar substancialmente seu conteudo"

E o art. 29 equipara não consumidores expostos a essa prática contratual a consumidores, ${ }^{15}$ de modo que a cláusula compromissória, como explica Antônio Junqucira de Azevedo, "era também nula em contratos de adesão realizados entre não consumidores" de acordo com o bastante citado art. 51, VII.

Mas, com a regra específica do $\S 2^{\circ}$ do art. $4^{\circ}$ da Lei de Arbitragem, a nulidade deixa de ocorrer na forma ampla anteriormente determinada, como se verá.

Em primeiro lugar, insiste-se na explicação de que se o contrato de adesão tiver consumidor como parte, è nula de pleno direito a cláusula compromissória nele inserida. pois trata-se de contrato de consumo.

Já quanto aos contratos de adesão entre não consumidores, deve-se observar o disposto no $\$ 2^{\circ}$ do art. $4^{\circ}$ da Lei n. 9.307/96, cuja redação í a seguinte: "nos contratos de adesão, a cláusula compromissória só terá eficácia se o aderente tomar a iniciativa de instituir a arbitragem ou concordar, expressamente, com a sua instituição, desde que por escrito em documento anexo ou em negrito, com assinatura ou visto especialmente para essa cláusula"

is "Art. 29. Para o fim deste Capiulo (V- Das Práticas Comerciais) e do seguinte (VI- Da Proteção Comercial), equiparam-se aos cunsumidores todas as pessoas determináveis ou não. expostas às práticas nele (sic) previstas" 
Verificam-se, assim, duas hipóteses nas quais é admitida a cláusula compromissória em contratos de adesão.

Pela primeira, a cláusula compromissória só terá eficácia se o aderente tomar a iniciativa de instituir a arbitragem, ou seja, a cláusula só vincula o policitante, não conduzindo necessariamente à solução arbitral de futuro e eventual litígio: bastará que o aderente prefira a via judicial para que não se instaure a arbitragem.

Carlos Alberto Carmona coloca que essa hipótese contém efetivamente fórmula que "protege o contratante mais fraco" pois querendo esse "ver solucionado conflito de interesses pela via arbitral, dará início ao procedimento, contra o quê não poderá opor-se o contratante mais forte; e, não querendo optar pela viu arbitral, bastará ao oblato propor demunda iudicial, contru o quê também não poderá opor-se o policitante" 16

A segunda hipótese, por sua vez, decorre de subemenda apresentada na Câmara dos Deputados, que procurava, de fato, aumentar a garantia do aderente contra eventuais abusos do policitante. ${ }^{1 ?}$

No entanto, o resultado obtido, se interpretado isoladamente, sem ter em conta os dispositivos protetivos do CDC, levaria a abusos da parte mais forte.

De fato, teríamos que a cláusula compromissória seria eficaz se o aderente concordasse expressamente com ela, a vistando ou determinando tal aceitação em documento escrito e assinado.

Mas, dessa maneira, o oblato permaneceria sujeito à vontade do contratante mais forte. pois. como escreve Antônio Junqueira de Azevedo, "a verdade é que quem assina, uma vez, 'continua na sua' e põe visto, mais uma ou duas vezes, nas mesmas condições" 18

Assim, a interpretação a ser feita deve levar em conta que o Código de Defesa do Consumidor considara nulas as cláusulas contratuais que determinem a

16 CARMONA, Carlos Alberto. Arbitragem e Processo: um comentário à Lei n. 9.307/96. São Paulo: Malheiros, 1998. p. 85.

17 Era a seguinte a redação original do $\S 2^{\circ}$, do art. $4^{\circ}$ : "Nos contralos de adesão, a cláusula compromissória só terá eficácia sc o aderente tomar a iniciativa de instituir a arbitragem, ou concordar. expressamente com a sua instituiçâo" Percebe-se, por esse dispositivo, que o legislador lidava com duas iniciativas para instituir a arbitragem: a do oblato, que vincularia o policitante, e, a do policitante, que não vincularia o oblato, a não ser que com o seu consentimento expresso com o início das atividades do árbitro, não havendo possibilidade de ser imposta a concordância prévia quanto à instituição da arbitragem, já que somente com a aceitação dos árbitros é que se dá por instituída a arbitragem (vide ('arlos Alberto Carmona. Arbitragem e processo: um comentário à Lei n. 9.307/96, p. 86). Ainda, deve-se colocar que, com essa redação, o art. $4^{\circ}, \S$ $2^{\circ}$ da Lei n. 9.307/90 retirava a importância do inciso VII do art. 51 do CDC, já que a arbitragem só seria instituida se a parte mais fraca o descjasse.

18 AZEVEDO, Antônio Junqueira de. A arbitragem e o Direito do Consumidor. Direito do ('onsumidor, n. 23, p. 33-40, jul./set. 1997. p. 39. 
utilização compulsória de arbitragem, de modo que só poderá a cláusula compromissória inserida em contrato de adesão ter eficácia em duas situações.

A primcira, já comentada, ocorre quando, após o surgimento do conflito. o oblato tomar a iniciativa de instituir a arbitragem. A segunda, quando o oblato concordar expressamente com a instituição da arbitragem, e desde que previamente cientificado da inserção daquela cláusula no contrato.

Nesse caso, o oblato deverá ter tido ciência da presença de cláusula compromissória no contrato ("por escrito, em documento anexo ou em negrito, com assinatura ou visto especialmene para essa cláusula"), e, após o surgimento do conflito e da pretensão do policitante de instaurar a arbitragem, deverá concordar expressamente com o início desse procedimento. ${ }^{19}$

Enfim, conclui-se que. nos contratos de consumo, sejam eles de adesão ounão, a cláusula arbitral é nula de pleno direito, mas a arbitragem pode ser instituída por meio do compromisso. Quanto aos contratos de adesão não-referentes a relação de consumo, a arbitragem poderá ser instiluida se a iniciativa for do oblato, ou se esse, previamente cientificado da existência da cláusula compromissória, concordar expressamente com a instituição do juizo arbitral.

São Paulo, fevereiro de 2005

Refurências

AlVIM, Arruda; ALVIM, Thereza; ALVIM, Eduardo Arruda; MARINS, James. Código do Consumidor Comentado. 2. ed. São Paulo: Revista dos Tribunais, 1995.

AZEVEDO, Antônio Junqueira de. A arbitragem e o Direito do Consumidor. Direito do Consumidor, n. 23. p. 33-40, jul./set. 1997.

BENTO, Leonardo Valles. A Arbitrabilidade dos I itígios de Consumo. Revista de Direito Econômico Internacional, ed. n. 3, ciez. 1997.

19 José Geraldo Brito Filomeno expressa esse mesmo entendimento, embora o estenda para a hipótese de ser parte no contrato um consumidor. Escreve: "somente quando o consumidor concordar expressamente, $e$ desde que previamente cientificado quamto à inserçäo daquela cláusula seria ela válida, até para os efeitos dos próprios dispositivos da lei específica a respeito. consoante. aliais, expressa disposição do art. $4^{\circ}$. $\$ 2^{\circ}$ da lei $9.307 / 96$ ", e complementa que ao consumidor, ademais, dever-se-ia facultar "a indicação de seu próprio árbitro. além do contratuaimente previsto, indicação tal que poderia recair na pessoa de algum técnico em defesa do consumidor, na de advogado especializado, ou noutra pessoa qualquer, desde que goze de sua plena confiança'" (FILOMENO, José Geraldo Brito. Conflitos de Consumo e Juizo Arbitral. Direiro do Consumidor, n. 21. p. 39-50, jan./mar. 1997, p. 50). 
CARMONA, Carlos Alberto. Arbitragem e Processo: um comentário à Lei n. 9.307/96. São Paulo: Malheiros, 1998.

ETCHEVERRY, Carlos Alberto. A nova lei de arbitragem e os contratos de adesão: algumas considerações. Ajuris: Revista da Associação dos Juizes do Rio Grande do Sul, v, 24, n. 69, p. $347-$ 358, mar. 1997.

FILOMENO. José Geraldo Brito. Conflitos de Consumo e Juizo Arbitral. Direito do Consumidor, $\mathrm{n}$. 21, p. 39-50, jan./mar. 1997.

GOMES, Orlando. Contratos. 17. ed. Rio de Janeiro: Forense, 1998.

NERY JU'NIOR, Nelson; NERY, Rosa Maria Andrade. Código de Processo Civil Comentado e a legislação processual civil extravagante em vigor. 4. ed. São Paulo: Revista dos Tribunais. 1999.

PUGGINA, Marcio Oliveira. Arbitragem ou jurisdição privada? Ajuris: Revista da Associação dos Juizes do Rio Grande do Sul, v. 24, n. 69. p. 359-368, mar. 1997.

SHIGUEMATSU, Plinio José Lopes. A Problemática da Cláusula Compromissória nos Contratos de Adesão. In: CASELLA, Paulo BORBA. Arbitragem: lei brasileira e praxe internacional. 2 ed. São Paulo: LTr, 1999. p. 438-449. 